\title{
Liberación y deliberación para la paz: una reflexión sobre los diálogos de paz en Colombia*
}

\author{
SONIA JULIANA GRANADOS MORA** \\ CARLOS MAURICIO GUERRERO OSPINA ${ }^{* * *}$
}

\section{INTRODUCCIÓN}

En el marco de la investigación Cátedra de la paz, una perspectiva filosófica en clave kantiano-discursiva que desarrolla el semillero "Enkantados: Kant y nosotros" de la Facultad de Filosofia y Letras de la Universidad Santo Tomás, en este artículo nos proponemos abordar dos aspectos necesarios y complementarios -aunque no exclusivos- que debemos tener presentes

* Este artículo fue elaborado por el semillero Enkantados: Kant y nosotros, resultado de investigación del proyecto "Cátedra de la paz: una perspectiva filosófica en clave kantiana discursiva”. Nota: Una versión inicial de este texto fue presentada en el Congreso Internacional de Pensamiento Americanista (CIPA), que tuvo lugar en el Instituto Universitario de Envigado, Colombia, en agosto de 2016.

** Asistente de catalogación en el Siglo del Hombre Editores. Egresada de la licenciatura en Filosofía y Lengua Castellana de la Universidad Santo Tomás. Estudiante de la Maestría en Filosofía Latinoamericana en la misma institución. Correo electrónico:soniagranados@usantotomas.edu.co.

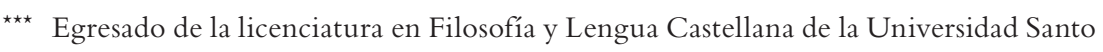
Tomás. Estudiante de la Maestría en Filosofía Latinoamericana en la misma institución. Correo electrónico: carlosguerreroo@usantotomas.edu.co. 
a propósito de la construcción de un país en paz: la deliberación racional y la praxis de liberación.

Partiendo del supuesto de que la paz en Colombia no se logra firmando unos documentos en la Habana entre las farc y el Gobierno y entendiendo por paz el estado propio de una sociedad que está en capacidad de canalizar los conflictos, no por la vía armada, sino por mecanismos institucionales y democráticos, consideramos que desde la filosofia debemos retomar el problema del diálogo como único medio legítimo de encuentro y tratamiento de los conflictos que en cualquier caso pueden surgir entre los miembros de una sociedad.

El principio moral del discurso, según Karl-Otto Apel (1985), nos indica que en una situación que se torna conflictiva, necesariamente debemos reconocer y escuchar a las otras personas como iguales a nosotros mismos, con las mismas necesidades básicas y las mismas capacidades para defender con argumentos los propios intereses, si lo que deseamos es resolver conflictos sin recurrir a la violencia. Sin embargo, tenemos presente la debilidad material de esta propuesta cuando resulta dificil pensar que las personas reales, con necesidades e intereses privados y situadas en condiciones de desigualdad, estén dispuestas a argumentar con otras personas reales para poder llegar a un acuerdo sobre asuntos que les competen a todos.

Por esta razón, vemos la necesidad de recurrir a la propuesta ético liberadora del filósofo latinoamericano Enrique Dussel.Dussel (2009), que reconoce el problema práctico del planteamiento de la ética discursiva al cuestionar la pretensión de simetría que deben alcanzar todas las personas participantes de un diálogo para argumentar con sentido. Es decir, que muchas de las personas que participan de diálogos para resolver conflictos no estarán dispuestas a abandonar sus intereses particulares, lo que repercute en la exclusión de los menos afortunados y menos capacitados. Por eso Dussel (2009) propone la legitimidad de la praxis liberadora, esto es, una acción orientada a cuestionar y transformar las condiciones reales de exclusión que no permiten a los menos aventajados participar y tener voz en asuntos de importancia vital. En otras palabras, lo que nos proponemos es resaltar, por una parte, la importancia que tiene la argumentación como medio idóneo para llegar a acuerdos normativos sin recurrir a la violencia, y por otra, la necesidad de recurrir a políticas de justicia social 
y mecanismos prácticos de inclusión que le den piso material a consensos normativos incluyentes en un país en conflicto.

Ahora bien, basados en la reconstrucción de este marco filosófico, en el siguiente apartado proponemos un análisis general sobre los intentos del gobierno por dialogar con los actores insurgentes, con el fin de reivindicar la necesidad del diálogo y la inclusión del otro como condiciones necesarias -aunque no suficientes- para alcanzar la paz en Colombia.

Como es sabido, en Colombia han persistido los intentos de paz consensuada entre actores históricamente beligerantes, pero también son conocidos los fracasos que incluso llegaron a intensificar la violencia y la represión. A raíz de estos fracasos, surge la sospecha de que recurrir a los procedimientos formales del diálogo racional para resolver conflictos normativos ha constituido un mecanismo espurio que oculta las verdaderas intenciones de los participantes para engañar y debilitar al enemigo.

Sin embargo, con los actuales diálogos de paz llevados a cabo en La Habana, confirmamos que a pesar de los fracasos acumulados en la historia, continúan los intentos de resolver los conflictos armados por vías dialógicas. Es más, consideramos con lo anterior que, en línea con la propuesta ético-discursiva del profesor Karl-Otto Apel, el diálogo o discurso argumentativo termina siendo la única vía legítima para resolver cualquier tipo de conflicto que evite el uso de la violencia (2004), porque es el diálogo racional y no otro modo de comunicación humana, el que nos exige el reconocimiento de la igualdad de derechos de todos los afectados por una norma y la obligación de responsabilizarnos para que todos los argumentos puedan ser escuchados y sopesados en la toma de decisiones que nos concierne. Sólo de esta manera, según los postulados de la ética discursiva, puede legitimarse la validez de los acuerdos logrados en las deliberaciones.

No obstante, reconocer y escuchar a las otras personas como iguales a nosotros mismos, con las mismas necesidades básicas y las mismas capacidades para defender con argumentos sus intereses, resulta bastante complejo en una situación condicionada por factores sociales, políticos y económicos. Pero para Apel (2006), la perspicacia de la ética del discurso consiste en que del principio moral del discurso argumentativo se puede derivar la obligación de responsabilizarse por lograr que todos los afectados de un acuerdo tengan posibilidades de participar en el diálogo bajo condiciones de igualdad. 
A pesar de los esfuerzos de Apel (2006) por darle realidad histórica al diálogo, en el debate que se llevó a cabo entre el filósofo alemán y el filósofo argentino Enrique Dussel (2009), se problematizó la pretensión apeliana de derivar de la ética del discurso una ética de la responsabilidad. El filósofo argentino niega esta deducción y agrega que sería ingenuo pensar que los participantes efectivos del discurso estén dispuestos a favorecer la participación de todos los afectados en contra del beneficio de sus propios intereses. Para Dussel (2009), son la huelga, la revolución y otras formas de resistencia social y política, los medios efectivos que tienen todos los afectados para interpelar a la comunidad que argumenta y entrar a participar en la toma de decisiones. Es la praxis de liberación, por tanto, la única vía legítima para que los argumentos del pueblo sean escuchados en circunstancias de exclusión.

Ahora bien, Enrique Dussel (2009) nos dice que la praxis de liberación no puede remitirse exclusivamente a acontecimientos excepcionales como la revolución, entendida como la confrontación que busca establecer un nuevo sistema completo de eticidad. Para el latinoamericano, la ética de la liberación es también una ética de la vida cotidiana, del día a día; por eso cree que cada uno de nosotros, como sujetos humanos concretos, somos actores en potencia de la praxis liberadora (2009).

Por nuestra parte, validamos ambas posiciones como legítimas y necesarias en un país en guerra con tránsito hacia la paz, y estamos convencidos de la importancia del papel de la educación para construir el país que tanto queremos, un país donde sus ciudadanos reflejen en el día a día la disposición de resolver moralmente los conflictos y de reconocer la importancia de la diversidad de opiniones sin la necesidad de recurrir a la violencia.

\section{MARCO TEÓRICO}

Apel: el dí́logo COMO VÍA LEGÍTIMA PARA

LA RESOLUCIÓN DE CONFLICTOS

Desde el principio nos es necesario recordar que la ética del discurso es ante todo una ética de raigambre kantiana: el universalismo de la filosofia moral kantiana, posibilitado por el uso práctico de la razón, es retomado por la ética del discurso y transformado en un nivel intersubjetivo 
del lenguaje. Ese universalismo kantiano nos permite pensar en que, tal como nos lo dice Adela Cortina (1988), existe algo común en todos los hombres, algo que nos hace semejantes y que nos permite prescribir normas de valor incondicionado. Esta facultad que posibilita lo universal en sentido moral es lo que Kant llama razón práctica -o comunicativa, en su versión apeliana-, la cual, según la filósofa española, constituye lo más propio de la identidad humana y renunciar a ella redundaría en la pérdida de nuestra propia humanidad.

Por su parte, el profesor Apel (2006) nos dice que el discurso argumentativo es aquella modalidad de la comunicación humana que posee carácter irrebasable para todo pensamiento que pretenda justificar su validez, porque todo aquel que desee argumentar contra la validez de la argumentación como medio legítimo para el entendimiento, estaría cayendo inevitablemente en contradicción performativa. De manera que el discurso argumentativo tendría una relación de identidad con la conducta racional del ser humano, porque si de lo que se trata es de resolver conflictos normativos, sólo podemos recurrir a la argumentación como único recurso posible para evitar las vías de hecho (Cortina, 1988).

Ya en el nivel filosófico de la fundamentación discursiva, Apel (2006) nos dice que son las reglas morales de la argumentación los presupuestos normativos necesarios para dotar de sentido a todo intento de intervención racional con miras al consenso. Si no presuponemos en nuestras intenciones dialogantes las reglas morales de la argumentación, dice el filósofo, los posibles acuerdos fácticos que puedan lograrse entre los hombres siempre llevarían a la imposición de la fuerza en favor del interlocutor dominante o del más astuto.

Es el concepto de la comunidad ideal de comunicación el presupuesto que nuestro filósofo descubre como obligatorio en los diálogos con sentido. Toda persona que desee argumentar honestamente acepta de antemano su pertenencia a la comunidad ideal de comunicación, lo que significa que acepta indiscutiblemente el reconocimiento de que todos los interlocutores reales y posibles afectados por la deliberación, comparten el mismo derecho de ser escuchados y la misma obligación de escuchar a los demás, bajo condiciones de igualdad y con el interés objetivo de llegar a un acuerdo que todos puedan aceptar y del que todos puedan 
responsabilizarse. Dicho de esta manera, si lo que deseamos es argumentar en "serio", en sentido apeliano, inmediatamente aceptamos nuestra pertenencia a una comunidad moral y, simultáneamente, aceptamos la obligación de responsabilizarnos por generar las condiciones reales para que todos los afectados por las normas puedan participar en las discusiones.

No obstante, "como principio regulativo que es, nunca será real” (Apel, 1985, p. 408). No hay que perder de vista que el concepto de comunidad ideal de comunicación funciona como una utopía que regula y otorga sentido a nuestras acciones. Jamás se han visto y jamás se podrán ver argumentadores indiscutiblemente 'serios', ni en Colombia ni en ninguna parte, pero lo importante es que vayamos acercándonos progresivamente a esta modalidad ideal de comunicación.

Lo particular de esta comunidad moral es que todos los miembros de ella deben trascender sus diferencias empíricas (económicas, sociales, políticas, etc.) para poder argumentar honestamente. Sin embargo, ¿es posible que en la vida real todos los individuos que desean participar en un diálogo estén dispuestos a suprimir sus diferencias empíricas para lograr un consenso universal? Evidentemente no, y Apel (2004) lo reconoce:"son precisamente las condiciones de aplicabilidad de una ética de la comunidad comunicativa ideal las que aún no están, en absoluto, dadas" (p. 67). Para solucionar el problema, nuestro filósofo recurre a la consideración de la ética del discurso como una ética de la responsabilidad.

Apel (2004) nos dice que es necesario que las condiciones ideales de la argumentación, a saber, la regulación de todos los posibles conflictos normativos por medio de discursos libres de dominación, se materialicen para poder argumentar honestamente. Pero como ya dijimos, es algo imposible dado que la comunidad ideal de comunicación es un presupuesto que nunca podrá darse en la experiencia. En palabras de nuestro filósofo, sería inmoral pedirle a un sujeto que actúe únicamente bajo las prescripciones de la comunidad ideal de comunicación sin prestar atención a las posibles consecuencias que puedan resultar de sus actos (2004). De modo que no sería moralmente aceptable ni responsable exigirle a un hombre que reconozca los derechos de todos los demás a la libre participación en las decisiones públicas, aunque sus propios derechos no sean reconocidos por los demás, porque si nuestra persona actúa únicamente 
por sus buenas intenciones, simultáneamente será objeto de manipulación estratégica por parte de los otros interlocutores y el consenso se verá parcializado en favor de algunos pocos intereses.

Para realizar una aplicación responsable de la ética del discurso, entonces, Apel recurre al principio de complementación. Según nuestro filósofo, una posibilidad que se ha realizado en la historia para exigir la aplicación responsable del principio discursivo, es confiar en el Estado de derecho como garante de las condiciones normativas para el despliegue moral de los conflictos (2006). Es decir, es la necesidad de la existencia del Estado de derecho como el único capaz de monopolizar la violencia e imponer a la fuerza la aceptación igualitaria de los derechos de todos los hombres. La responsabilidad moral del individuo se vería complementada por la co-responsabilidad moral de todos los participantes reales y virtuales garantizada por el Estado de derecho.

Sin embargo, como el mismo autor lo reconoce, con la función posibilitadora del Estado de derecho no se soluciona completamente el problema de la aplicación responsable de la ética del discurso, porque ni siquiera en un Estado que funcione de manera óptima puede lograrse que efectivamente los hombres se corresponsabilicen por todos los demás (Apel, 2004), y para comprobarlo bastaría echar un vistazo a la historia. Ahora bien, nuestro filósofo finalmente resuelve el problema proponiendo la función teleológica que cumple el principio de la ética discursiva.

Para Apel (1985) la ética del discurso no solo obliga a que los argumentantes acepten su pertenencia a una comunidad moral ideal, sino que además los obliga a realizar progresivamente las condiciones de aplicabilidad necesarias para llevar a cabo el discurso en la situación particular donde se efectúen los diálogos fácticos. Por eso, el principio racional de la ética del discurso no solo tiene una función teórica, sino que posee una nueva función que involucra directamente una ética de la responsabilidad por comprometerse en la realización de las condiciones normativas ideales.

En este sentido, argumentar nos obliga a aceptar nuestra pertenencia tanto a una comunidad moral que es ideal, como a una comunidad real de argumentadores que está situada en la historia bajo condiciones asimétricas para la resolución de conflictos, que debe ser modificada progresivamente, en la medida de lo posible, apuntando siempre a la realización de 
la comunidad moral en ella. Estarían, pues, todos los interlocutores reales y posibles en un diálogo fáctico con pretensión de consenso universal, comprometidos con todos los demás participantes para que a largo plazo todos los argumentos puedan ser escuchados y tenidos en cuenta sin importar las diferencias de poder o los intereses estratégicos que puedan presentarse.

\section{DUSSEL. LA PRAXIS DE LIBERACIÓN COMO VÍA} EFECTIVA PARA LA RESOLUCIÓN DE CONFLICTOS

En el debate que se realizó a comienzos de la década de los noventa del siglo XX en el marco de los diálogos Norte-Sur, el filósofo argentino-mexicano Enrique Dussel problematiza la pretensión que tiene Apel de derivar una ética de la responsabilidad a partir del puro formalismo discursivo. Sin embargo, en el libro que publicó nuestro filósofo latinoamericano casi diez años después del debate con el alemán: La ética de la liberación en la época de la globalización y exclusión, incorporó en la ética de la liberación aspectos relevantes de la ética del discurso, como la necesidad de transformar la filosofia solipsista kantiana de la validez universal de la moral, a una filosofia del consenso universal que implique necesariamente la dimensión intersubjetiva del lenguaje (Dussel, 2009). Dussel deja claro en este libro cuál es la crítica dirigida a la ética del discurso desde la ética de la liberación y reconstruye a su vez la propuesta ético liberadora teniendo en cuenta los aportes de Apel y las críticas que sostiene el latinoamericano.

Dussel (2009) critica al filósofo alemán debido a que este no puede descender de la parte de fundamentación teórica y formal de la ética del discurso hacia lo concreto, a la vida real del ser humano. En otras palabras, para el latinoamericano la ética del discurso no logra superar el formalismo de tradición kantiana por no integrar desde el comienzo el principio ético material universal, lo que impide dar a la ética discursiva el paso para ser considerada como una ética de la responsabilidad. Esto se debe a que, según el argentino, Apel tiene una visión reductiva del aspecto material de la ética, ya que reduce lo material a un problema de concepciones particulares de la vida buena sin carácter universal, concepciones que no son temas de relevancia para la ética del discurso.

Para Apel (2004), la ética del discurso sólo es posible dentro del discurso mismo, es decir, es en el discurso argumentativo donde se deducen 
los presupuestos morales necesarios para el mismo acto de argumentar, lo que lleva a pensar a Dussel (2009), efectivamente, que en la fundamentación de la ética del discurso no se hace referencia a ningún aspecto material del ser humano, sino sólo a la formalidad de las reglas y relaciones ideales y universales para argumentar. Para el argentino esto acarrea una grave contradicción porque la ética de la responsabilidad está determinada normativamente, no por una razón ético-discursiva, comunicativa, sino por una razón de tipo estratégico, instrumental. Es decir, que en una ética de la responsabilidad los individuos, que están en condición de asimetría, no son sujetos morales cien por ciento racionales que argumentan para llegar a un entendimiento basado en un consenso universal, sino que parten de la razón que busca los medios necesarios para satisfacer ciertos fines, fines que son particulares a cada individuo y que están marcados por intereses subjetivos (de poder, económicos, sociales, etc.). Apel cree que la responsabilidad por las consecuencias de las acciones normativas que se derivan del principio ético discursivo obliga a los individuos a actuar de tal manera que las condiciones morales para el diálogo sean alcanzadas progresivamente. Pero según el argentino, lo único que obtiene Apel con esto es que la ética del discurso dependa de una ética de la responsabilidad, porque sólo por medio de la ética responsable es posible alcanzar progresivamente las condiciones ideales del discurso, condiciones sin las cuales el discurso mismo no tendría sentido. Dice el argentino:

dicha Ética de la Responsabilidad no cuenta con normas que puedan deducirse o fundarse en la ética del discurso, sino sólo con normas estratégicas o instrumentales. Se cae así en una contradicción, ya que la ética del discurso deberá confiar y esperar, por no contar con recursos propios para efectuar concretamente la simetría entre los argumentantes reales, en una ética puramente estratégica e instrumental y, en palabras de Apel, frecuentemente cínica.Y no cuenta ya con esos recursos porque ha situado desde su origen incorrectamente el problema de la ética material. (2009, p. 186)

Y precisamente se presenta esta dificultad en el alemán, según Dussel, porque la ética de la responsabilidad se inscribe dentro de las éticas materiales, concretas, cuya función material ha sido excluida en la parte de 
fundamentación del discurso. Si Apel hubiera añadido desde el comienzo la dimensión material y no meramente racional del ser humano, dice el argentino, le hubiera sido posible fundamentar un principio material universal de la ética, y deducir, por tanto, una ética de la responsabilidad. Pero como de lo meramente formal no se puede deducir directamente algo material (como en el imperativo categórico de Kant), su tarea le fue imposible.

Para Dussel (2009) el problema es que la ética del discurso hace de la argumentación correcta la condición para la vida humana misma, cuando lo correcto debería ser al revés: "es decir, aquí la sobrevivencia (biológica y cultural) se deduce del principio y es condición de posibilidad de la argumentación, siendo la argumentación la referencia irrebasable, y no viceversa" (p. 187). Mientras para Apel lo irrebasable en todo discurso sobre lo ético es la moralidad necesaria y universal para argumentar honestamente, para Dussel lo irrebasable es la vida humana misma, su reproducción y desarrollo, porque el argumentante que no tiene vida o que no está en condiciones para ser escuchado en el diálogo, no puede argumentar, no debe argumentar, porque no será nunca reconocido como posible argumentador.

Como vimos más arriba, en la ética del discurso cualquier argumentador honesto debe admitir su pertenencia a dos comunidades, la ideal y la real. Para Apel (2006) existe una contradicción entre estas dos comunidades, pero existe también la responsabilidad moral de trabajar para que las condiciones ideales se realicen en la real. Sin embargo, el problema que Dussel señala es que en la comunidad real de argumentantes, los que discuten y llegan a acuerdos reales son aquellos que disponen de las condiciones económico-políticas para hacerlo. Son los sujetos que son ‘iguales' entre sí, porque esos acuerdos estarían excluyendo del diálogo a los otros que no son considerados como tales, es decir, se excluiría a los que no pueden participar del discurso argumentativo en la comunidad real de argumentantes porque carecerían de las condiciones reales para participar, no quedando para ellos otra salida que resignarse a aceptar los acuerdos alcanzados por los que sí están en condiciones de dialogar.

En contra del principio de responsabilidad moral de la ética del discurso, Dussel consideraría ingenuo pretender que sean los mismos participantes reales que tienen la posibilidad de argumentar y que traen consigo intereses económicos y políticos, los que se responsabilicen moralmente 
por trabajar para que a largo plazo todos los afectados puedan participar en la toma de decisiones que les corresponde, aun cuando sea probable que se presenten conflictos de intereses. Para los excluidos, según el argentino, la única posibilidad que tienen de ser escuchados y tenidos en cuenta en las discusiones sobre asuntos que les interesa "no puede depender de la responsabilidad moral de los que tienen el poder, sino de la praxis de liberación" (2004, p. 123).

La praxis liberadora transforma la realidad que oprime e imposibilita la vida y la participación del menos favorecido, exigiendo el reconocimiento del otro para establecer el diálogo y exigiendo materializar las condiciones necesarias para que puedan ser escuchados los argumentos y protegidos sus derechos. Para Dussel (2009), la huelga y la revolución constituyen los recursos válidos para que los afectados excluidos de la deliberación pasen de ser simples afectados por las consecuencias a participantes activos en la toma de decisiones. En este caso, el obrero, por ejemplo, sólo podría argumentar para sí mismo, porque el capitalista no escucharía sus propuestas. Necesitaría de la huelga como recurso para poder sentarse en la mesa de negociación con la garantía de que sus argumentos puedan ser sopesados en la búsqueda de consenso.

Dussel (2009) nos recuerda constantemente que la ética de la liberación es una ética de la vida, de la cotidianidad, no es una ética que tenga como único propósito la realización de acontecimientos absolutamente excepcionales (como la revolución), sino que se preocupa principalmente porque la víctima, sujeto humano individual y concreto, con cuerpo propio, que se encuentra en una situación adversa que no le permite reproducir y desarrollar su vida plenamente ni participar en las discusiones públicas que le afectan, pueda superar esas condiciones asimétricas y liberarse de la opresión que le impide vivir. Para el filósofo argentino, la praxis de liberación "es la acción posible que transforma la realidad (subjetiva y social) teniendo como última referencia siempre a alguna víctima o comunidad de víctimas" (p. 553).

Por tanto, la praxis de liberación también es considerada como una posible acción cotidiana que transforma las relaciones de dominación y exclusión que existen entre individuos aislados. De esta manera nos recuerda Dussel (2009): 
así, la revolución no es sino el momento extremo de un nivel de complejidad que comienza en su posición mínima por la transformación de una máxima de la vida cotidiana en referencia a una acción posible insignificante (p.e., desde el muy vulgar ¡Voy a escupir en el suelo!, y que debe ser transformada desde criterio y principio que se enuncia como la no negación del Otro, en algún aspecto que pueda redundar en la disminución de vida o participación simétrico discursiva de la víctima de la realización de tal máxima). (p. 533)

Como vemos, la praxis liberadora es una posible acción de transformación que cada uno de nosotros está en capacidad de realizar. En tanto seres humanos podemos modificar las intenciones de nuestros actos o el contenido de las normas que perjudican la reproducción y el desarrollo de cada sujeto, en favor de acciones que reconozcan los derechos y las necesidades de los demás (Dussel, 2009). Por esta razón, cuando actuamos en función de transformar nuestra realidad inmediata desde principios ético liberadores, estaríamos combatiendo directamente las normas y prácticas del sistema que reproducen la opresión de la vida y la exclusión en asuntos que nos afectan a todos.

\section{ANÁLISIS DE RESULTADOS}

A partir del enfoque ético-filosófico anterior, en este apartado mostraremos el análisis sobre algunos intentos de diálogo que varios presidentes colombianos procuraron sostener con grupos insurgentes, especialmente con las FARC. Estos resultados mostrarán los distintos intentos de diálogo y cómo los actores terminaban por desistir en estos esfuerzos racionales por la búsqueda de la paz. Los resultados de nuestro análisis confirmarán que en todos los casos los diálogos estaban destinados a fracasar porque no se garantizaron las condiciones de simetría entre los interlocutores. Sin embargo, concluimos que los diálogos de la Habana, además de confirmar esa disposición humana y racional al diálogo, abre un horizonte nuevo de posibilidades que en principio ofrecen mayores garantías para deliberar entre iguales.

El análisis de los resultados nos permitimos acompañarlos por un estudio del experto en diálogos de paz en el contexto colombiano, Marc 
Chernick, pues consideramos que de la mano de su estudio "Aprender del pasado: Breve historia de los procesos de Paz en Colombia (1982-1996)" podremos guiarnos cronológicamente y ver a la luz de su repaso histórico los esfuerzos o la ausencia del diálogo racional entre los actores del conflicto.

En el caso colombiano, suponemos de antemano que los intentos por perseguir la paz a través del diálogo y acordar la paz son el ejemplo de una actitud ética en sentido discursivo, que si bien los protagonistas no culminaron exitosamente, sí son el principio que nos permite pensar en la posibilidad de alcanzar un país más incluyente y democrático. Marc Chernick, director del Centro de Estudios Latinoamericanos de la Universidad de Georgetown, examina la historia de los acuerdos de paz en Colombia y en general en América Latina, pues su gran tesis sostiene que sólo a través del diálogo entre las partes sería posible la paz. Por la actualidad y la significancia de su estudio, nos dedicaremos a analizar sus consideraciones sobre lo histórico-político de los acuerdos de paz en Colombia.También serán de gran valor los aportes de los comisionados sobre la historia del conflicto y sus víctimas ${ }^{1}$, porque ellos, al igual que Chernick, analizan el aspecto histórico, no de los acuerdos de paz, sino del origen del conflicto, ya que, según las mesas de negociación en La Habana, si se identifican estos motivos de la permanencia del conflicto, se determinaría con mayor ligereza los pasos para alcanzar la paz.

En el momento en que Chernick escribe Aprender del pasado: breve historia de los procesos de paz en Colombia (1982-1996) (1996) los procesos de paz anteriores tenían una madurez de catorce años, pero al día de hoy esa madurez ha aumentado a treinta y cuatro años y el panorama ha cambiado considerablemente. Sin desconocer la variedad de estudios, especialmente el de la CHCV sobre el origen y la permanencia de la guerra civil colombiana, los primeros acercamientos a los diálogos de paz se hacen en 1982 con el interés del expresidente Belisario Betancur por crear el proyecto de amnistía, así como la Comisión de la Paz para la desmovilización a los grupos insurgentes de la época: Fuerzas Armadas Revolucionarias

1 La Comisión Histórica del Conflicto y sus Víctimas fue designada por el gobierno nacional y las FARC en 2014 con el fin de aclarar las causas y la permanencia del conflicto armado en Colombia, así como sus directos responsables. 
de Colombia - Ejército del Pueblo (FarC-EP), Ejército Popular de Liberación (EPL), Movimiento 19 de Abril (M-19), Ejército de Liberación Nacional (ELN) y la Autodefensa Obrera (ADO) (Acuña, s.f.). Para Chernick, el intento de Betancur por mantener los diálogos de paz no fracasó, como comúnmente se pensaría, sino que introdujo dos elementos que cambiaron la dirección del discurso político: reconocer la oposición armada como actor político y reconocer la necesidad de un proceso de "apertura democrática” (1996).

Las negociaciones del gobierno de 1982, que promovían el diálogo sobre lo agrario, legislativo, etc., al reconocer a la oposición como actor político (es decir, válido en tanto que la oposición también argumenta racionalmente), permitió el surgimiento de partidos políticos como la Unión Patriótica (1985). Pero las negociaciones y la tregua del gobierno de Betancur cayeron en 1987 por "falta de garantías" de ambas partes (Federación Colombiana de Municipios, 2014). En términos de balance, el diálogo instaurado y promovido por Belisario Betancur fue el primero que reconoció la validez del conflicto en términos políticos, es decir, asumió que existía una locución racionalmente válida por parte de una diferencia, lo que a su vez permitió el desarrollo de un mecanismo ético y legítimo: el diálogo.

Según Chernick, en 1986, al llegar al poderVirgilio Barco, se hizo una evaluación negativa de los esfuerzos del gobierno anterior acusando falta de organización, razón por la cual se crea la Consejería para la Reconciliación, Normalización y Rehabilitación de la Presidencia. Chernick afirma que el gobierno de Barco quiso "afirmar la autoridad del Estado como Estado" pretendiendo únicamente el desarme por parte de la insurgencia (M-19 desmovilizado el 9 de marzo- y el EPL el 16 de mayo de 1990), pero también permitió la creación de otros espacios para la reconciliación como los consejos municipales. Chernick resume la labor del presidente Virgilio Barco del siguiente modo:

En el fondo, el objetivo principal no era negociar una solución al conflicto armado, sino legitimar el Estado y deslegitimar la guerrilla. Es decir, para Barco podía haber negociaciones, pero ya no entre dos partes, sino entre un Estado que conscientemente representaba a la ciudadanía y unos grupos guerrilleros que cada vez eran menos legítimos, pero que 
podrían aspirar a participar en la vida política del país. La estrategia se resumió en el lema de "mano tendida; pulso firme" (1996, p. 2).

Las cosas así, resulta indicado pensar que, lo conveniente para el Estado o los gobiernos a cargo es combatir contra rivales ilegítimos que en todo caso deben ser destruidos y eliminados, porque sólo así pueden permitirse desplegar todo el potencial armado y justificar la necesidad de un gobierno que los enfrente con mano dura. De otro modo, es decir, del modo legítimo y democrático, el gobierno tomaría a su rival como un actor político y, por lo tanto, como un interlocutor válido para el diálogo entre iguales.

De 1986 a 1989 no hubo diálogos de paz y se logró una 'paz parcial' (Chernick, 1996), pues tras haberse desmovilizado algunos de los insurgentes, grupos robustos como las farC quedaron por fuera. En 1990 llegó a la presidencia César Gaviria y casi inmediatamente ordenó el bombardeo de Casa Verde, cuna de las FARC, acto ya de por sí diciente y consecuente con algunos de los mandatos del anterior presidenteVirgilio Barco (Segura. De comisiones de paz en la historia de Colombia 2015). Después del agotamiento político de todo el año 1991 a razón de la constituyente, en 1992 el resultado de una nueva Constitución fue, en términos de Chernick, "un país más democrático, aunque sustancialmente más violento" $(1996$, p. 3) porque la guerra civil parecía prolongarse año tras año entre ataques y contra-ataques.

Según como se manifiesta históricamente en el gobierno de Gaviria, allí también el problema central para la llegada a un acuerdo de paz fue la precaria participación en sentido dialogante de la insurgencia, porque el interés tanto de Gaviria como el de José Antonio Bejarano (en su época, consejero presidencial para la paz) era la desmovilización de las guerrillas y su reincorporación a la vida social, para lo que se creó la Dirección Presidencial para la Reinserción. Pero, ¿había temor de discutir abiertamente con las guerrillas? La tradición de la ausencia de diálogo en los gobiernos de Colombia no es única del expresidente Gaviria, porque como lo destacan algunos de los informes de la cHCv, los acuerdos que se pactaban pocas veces contaban con la participación como debe ser, según Adela Cortina (2008), de aquellos quienes estarían sujetos a las disposiciones a posteriori del acuerdo. Las conversaciones que involucran a todos los afectados, como medio para la consecución de la paz, o por lo 
menos de un acuerdo, son el punto de partida para la constitución de una nación que busca paz.

Por un lado, Chernick sostiene que "si el objetivo es la paz y la terminación del conflicto armado, un gobierno gana involucrando a la guerrilla en las grandes reformas estructurales, sentándola a la mesa, dándole crédito a sus proposiciones, haciendo de ella un sujeto de negociación y no un objeto de derrota" (1996, p. 3) y algo de cierto habría que señalar en este punto porque incluir a las distintas guerrillas dentro de un diálogo legítimo es como ponerlas de cierto modo al servicio de un Estado a favor de la paz.

Por otro lado, Tal y como lo enuncia Eduardo Pizarro en su libro Cambiar el futuro (2017), la paz en Colombia ha sido un reto esquivo, pues el conflicto se prolongó indefinidamente desde los primeros intentos por dialogar con la insurgencia en la década del 80. El conflicto armado colombiano ha sido uno de los más longevos según como lo muestra Pizarro (2017), y la dificultad que trae consigo esa prolongación es la imposibilidad para superarlo por medio de la negociación, pues entre más dure el conflicto, mayor reto significa para todos los actores involucrados, directa e indirectamente, dejar atrás las deudas ocasionadas por la guerra para darle vía a la confianza entre los que se disputan. Según Pizarro (2017), esta dificultad ha retrasado el desarrollo de la paz, así como también lo retrasó el que los gobiernos de momento no estudiaran y contaran con los avances o con los errores cometidos de las antiguas experiencias de negociación, y este error le costó a Colombia no solo la prolongación del conflicto, sino también poner en mayor grado de dificultad la consecución la paz.

Volviendo con el recorrido histórico de las negociaciones de paz en Colombia y luego de haber comentado el ataque a Casa Verde en diciembre de 1990, además de la génesis de la nueva Constitución colombiana en 1991, entre el año 91 y el 92 el gobierno nacional logró establecer diálogos en búsqueda de la paz con la Coordinadora Guerrillera Simón Bolívar, en Tlaxcala, México. La agenda, como es sabido, se vio frustrada ante la muerte del ministro Argelino Durán Quintero durante su secuestro, así que las FARC quedaron por fuera de toda negociación así como también el gobierno. Sin embargo, sí se concordó la paz con el Partido Revolucionario de los Trabajadores (PRT), el Quintín Lame y el EPL. 
Como se venía diciendo, tanto Barco como Gaviria coincidían parcialmente en la anulación de la figura del otro personificada por la insurgencia, restándoles su carácter de validez; pero en el gobierno de Samper, con todo y crisis presidencial, este le otorgó nuevamente el carácter político al conflicto. Samper requirió el llamado Informe de los Cien días y para el momento en que Chernick escribía su artículo, no había resultado sobre la posibilidad de la negociación. Lo que se supo es que Samper decretó (Decreto 2107 de 1994) la instauración de la Comisión de Acción para la Paz, pero se fundaron en los años siguientes: Comisión Facilitadora de Paz, Comisión de Conciliación Nacional, Consejo Nacional de Paz y la Asamblea Permanente de la Sociedad Civil por la Paz.Todas las anteriores respondían a problemáticas específicas distintas, pero que a fin de cuentas propendían por el diálogo para la paz entre el gobierno y sus antagonistas políticos. Para el periodista Hugo García Segura, esta "comisionitis" demuestra que "dichas instancias han servido, salvo pocas excepciones, para generar confusión e indefinición" (De comisiones de paz en la historia de Colombia, 2015)

El exceso de comisiones puede que complejice los procesos institucionales, y en este caso no solo Segura estaría en lo cierto, sino también el periodista León Valencia, desde una mirada distinta, con el artículo "El fracaso de la comisión histórica del conflicto" (2015). Para Valencia (2015) la CHCv fue un gran fracaso porque entre las muchas causas del origen, nunca dieron nombres concretos de los responsables del conflicto y su prolongación, propósito fundamental que dio inicio a la Comisión.

Pero continuando con el estudios histórico político de los diálogos de paz en Colombia, Andrés Pastrana como primer mandatario de Colombia intentó formalmente negociar la paz con las FARC entre 1998 y 2002; además continuó con la ejecución de la Oficina del Alto Comisionado para la Paz de la Presidencia de la República que había creado Samper, y a través del Consejo Nacional de Paz se constituyó la Mesa Nacional de Diálogo y Negociación. Asimismo, se concedió la conocida Zona de distención en el Caguán, destinada para el proceso de paz mediante la Resolución 85 del año 1998. La 'agenda común’ de la negociación “consagra las bases políticas, económicas y sociales de la negociación [...]. Lo principal en las negociaciones es el contenido de la agenda, concreta y realista, pero dirigida a los temas esenciales que originaron el conflicto" 
(Ballén Molina, 2009). El proceso de negociación iniciado por Pastrana no consistía en un proceso nuevo, pero sí era la renovación de los varios intentos fallidos desde 1982; porque, según como lo plantea Ballén Molina, el procedimiento de la negociación que intentó revivir Pastrana contenía los mismos puntos de las negociaciones pasadas. Mark Chernick no pudo conocer el resultado negativo de las negociaciones llevadas a cabo por el gobierno Pastrana, que finalmente concluyeron con la alocución presidencial el día 20 de febrero de 2002, y que las FarC desde algún sitio de las montañas colombianas respondieron así:

7. Una vez más la oligarquía colombiana impide que por la vía del diálogo se hagan los cambios estructurales, económicos, políticos, sociales y militares que requiere Colombia para salir de la profunda crisis en la que la han sumido históricamente los gobiernos liberal y conservador. 8. Durante tres años buscamos soluciones por la vía del diálogo y la negociación para los graves problemas que aquejan a 30 millones de colombianos sin que el Gobierno respondiera a estas necesidades del pueblo. Siempre se hizo el de los oídos sordos. La presencia de más de 30 mil compatriotas que participaron en las audiencias públicas, mesas redondas y con ponencias enviadas a la mesa con propuestas de cambios que democraticen la vida económica y política del país, así como la solicitud del Secretario General de las Naciones Unidas y el presidente de la Conferencia Episcopal en Colombia, corroboran la necesidad de estas transformaciones. (Reyes et al, 2002)

Para Ballén Molina, que coincide con Chernick, las negociaciones por la paz deben basarse en el cese bilateral del fuego, la incorporación al diálogo del Ejército Nacional y, por supuesto, de entes internacionales que cooperarían para evitar el rompimiento de las negociaciones.

Lo que Chernick no alcanzó a incluir en su corpus fueron los gobiernos de Álvaro Uribe y Juan Manuel Santos, así que a continuación en nuestros resultados presentaremos el perfil de ambos gobiernos.

Para estudiar los gobiernos de Uribe y Santos incluiremos el análisis Poder y violencia en Colombia, de Fernán González (2014). Según el profesor González, el gobierno Uribe profundizó la guerra en virtud de la paz a través 
de la intensificación militar en el campo colombiano. Hay que recordar que el expresidente Uribe no reconoció en su gobierno el conflicto ni la validez de la lucha de la guerrilla, motivo por el cual no hubo una negociación que hacer, puesto que la negativa del conflicto cerraba esa posibilidad.

En el gobierno de Uribe no hubo promesa ni mucho menos ejecución de un diálogo entre dos partes; de hecho, desde el gobierno de Uribe ni siquiera hubo un reconocimiento de las FARC como agente político. Es claro que la política de la Seguridad democrática estaba fundamentada en un principio belicoso que pretendía la paz a costa de una intensa guerra en el área rural. Por lo tanto, en este caso el gobierno de Uribe al pretender eliminar del diálogo al enemigo, quebranta el principio de diálogo entre seres racionales, pues, como varias veces él mismo y su gobierno lo manifestó, a las FARC había que eliminarlas, ya que solo hacían sangrar y envenenar a la patria.

Con el "Plan Patriota" puesto en marcha desde 2004 en Meta y Caquetá, y en el marco de la Seguridad democrática, las Fuerzas Militares de Colombia asediaron a la guerrilla y recuperaron espacios que habían sido tomados. González (2014) si bien reconoce la recuperación de estos espacios políticos y militares, muestra cómo el repliegue de las guerrillas en otras regiones comenzó a afectarlas.

Como lo dice el profesor González, la propuesta estratégica de Uribe para la terminación del conflicto consistía en una coordinación de lo jurídico, lo político, la población civil y lo militar, cuya conjugación no permitía sino el rechazo general hacia la insurgencia (González, 2014). Con esta mega coordinación, Uribe logró que las FARC fueran vistas como agentes terroristas por los ojos de la población civil en general, a la cual Uribe alentaba en esa guerra patria que era válida según su discurso de desarrollo, porque a su juicio y recordemos, el desarrollo del país se daba únicamente con la eliminación de la insurgencia (2014). En las cifras que ofrecía el gobierno Uribe se veía la disminución del secuestro y la violencia, pero por otro lado, las ONG denunciaron el asedio político que el gobierno les hizo por no estar de acuerdo y en abierta oposición con las políticas militares, que como resultado llevó a una fuerte polarización.

Lo que hay que agregar a estas alturas de este escrito es que, a lo largo de la historia colombiana desde la creación de las guerrillas y a partir del 
asesinato de Jorge Eliecer Gaitán, como consecuencia casi directa y para la defensa del pueblo civil se crean la "contraguerrillas", que en otras palabras no son sino el fenómeno del paramilitarismo más tarde. El paramilitarismo se convirtió en otro de los tantos fenómenos de la guerra en Colombia, y sin querer profundizar en esto, debíamos mencionarlo porque dentro las negociaciones con la insurgencia colombiana existió un intento en el gobierno de Uribe con los jefes paramilitares.

Como dijimos, las negociaciones que el gobierno de Uribe mantuvo con las Autodefensas Unidas de Colombia no son examinadas en este artículo. Sin embargo debemos destacar que el proceso de diálogo con las AUC estuvo no solo lejos de darse en medio del cese al fuego (como se hubiera esperado en un diálogo normal), sino que tampoco fue transparente. En la llamada Ley de Justicia y Paz se promovió la desmovilización de los grupos paramilitares, pero "lejos de ser un instrumento de verdad, justicia y reparación, conducía al a impunidad" (González, 2014, p. 452), no sólo porque los tiempos máximos de condena contemplados en la ley no superaban los ocho años, sino también por el engaño de varios narcotraficantes paramilitares, que en virtud de la ley no fueron extraditados sino condenados, con algunos de esos años que jamás superaron los ocho, como simples paramilitares. Pero como dijimos, el tema del paramilitarismo no es analizado acá, pero debía mencionarse porque hizo parte de la agenda del gobierno Uribe en favor de lo que él denominaba "paz".

Chernick, en una entrevista publicada en 2015 vía internet a través de confidencialcolombia.com, niega que las desmovilizaciones de los paramilitares fueran un ejemplo de procesos de paz, justamente por un principio al que acá hemos aludido y es que la paz se dialoga es con los enemigos. El proceso dialógico que busca la restauración o la consecución de la paz debe ir acompañado de un análisis profundo sobre el origen y las causas del conflicto, pues desde allí se podrían esclarecer vías para la terminación del conflicto con la promesa de no repetición.

Si bien tuvo lugar el proceso de desmovilización con los paramilitares a través de la Ley de Justicia y Paz en el gobierno de Uribe, su política no fue suficiente para emprender un camino basado en las máximas de la ética que implica el diálogo, pues es difícil construir las bases sólidas que permitan la argumentación cuando uno de los actores no reconoce 
al otro como igual. Es claro que para el gobierno Uribe no era de imperiosa necesidad entablar un proceso de negociación.

Una vez Juan Manuel Santos asume su cargo como primer mandatario de la república, se hace evidente que uno de sus intereses es la futura pacificación de Colombia. Ahora en esta sección de los resultados mostraremos que finalmente los principios que permiten la argumentación racional se dan con las negociaciones de La Habana. Por eso se hace necesario exponer en orden cronológico, pero somero, desde el origen de los diálogos de paz, su desarrollo, sus enredos, la firma de los acuerdos pactados en La Habana y firmados en Colombia seis años después, hasta la puesta en vigencia de la Justicia Especial para la Paz. El resultado concreto de esta investigación apunta a que en los diálogos de La Habana se materializó la propuesta discursiva que propugna la idea de reconocimiento de la dignidad encarnada por el enemigo en tanto que este también es un ser racional capaz de argumentar.

En diciembre de 2010 el recién electo presidente Juan Manuel Santos intenta acercamientos con las FARC. Este primer acercamiento sirvió de enlace entre las dos partes para que ambas se interesaran por continuar el contacto y establecer un diálogo. Ya para el principio de 2011 se da la primera reunión entre el GN y las FARC, que había sido vista con aceptación por Alfonso Cano. Es importante tener en cuenta que, desde el principio de estos acercamientos hasta muy adelante, el hostigamiento militar por parte del Ejercito Nacional no se mermó. Juan Manuel Santos antes de esta reunión había recurrido a la figura de Raúl Castro (Cuba) para mostrarle su iniciativa de diálogo, motivo por el cual los hermanos Castro buscaron ratificar si los intereses de las altas esferas de las FARC eran en efecto estos, los del diálogo. Meses más tarde desde Tumaco, el presidente Juan Manuel Santos reconoce la existencia del conflicto armado colombiano. Con esta declaración se le permite un lugar a la posibilidad de una salida no militar. Este reconocimiento del conflicto tiene efectos jurídicos, pues como telón de fondo se encuentra el estudio la Ley de Víctimas, en la cual no habría distinción entre víctimas y victimarios si no se reconocía el fenómeno del conflicto. En efecto, este estatus político cambia toda la perspectiva que se tenía sobre los procesos de paz, pues, como se indicó anteriormente, los gobiernos anteriores no reconocían políticamente 
a las FARC como actores válidos para ser tenidos en cuenta en un diálogo. Con esta definición del conflicto armado se promueve la comprobación de la existencia del otro, en este caso, las FARC, no de justificar la beligerancia, sino más bien validar la existencia de la guerra con fines para su terminación a través de la negociación.

Desde las montañas de Colombia, Alfonso Cano confirma la posibilidad de establecer conversaciones entre las FARC y el GN a través de la construcción de un escenario de diálogo, pero afirmando que no habría desmovilización, pues esto sería una traición al compromiso ideológico que los mueve. Como el cese al fuego no se da, cae Cano en una maniobra de guerra y Timonchenko asume el cargo de máximo jefe de las FARC. El 23 de febrero de 2012 se da el primer encuentro entre el GN y las FARC en La Habana, Cuba. Los negociadores por parte de las FARC son Marcos Calarcá, Rodrigo Grande, Andrés París y Mauricio Jaramillo; por parte del gobierno se encontraban Enrique Santos, Frank Pearl y Sergio Jaramillo. Noruega se vincula al proceso y acompaña en adelante las negociaciones y mesas de discusión. El mensaje de este primer encuentro fue coherente entre ambas partes, pues el objetivo común era la terminación del conflicto. De este primer encuentro puede entenderse que de parte y parte hubo un nivel de confianza que permitió creer mutuamente en las intenciones del otro.

Las conversaciones exploratorias continuaron y así lo anuncia el gobierno Santos en una alocución nacional, y más tarde en septiembre 03 de 2012, el presidente da a conocer que habrá cinco puntos a tratar en el "Acuerdo general para la terminación del conflicto". De manera breve esta fue la agenda: desarrollo agrario, participación política, fin del conflicto, drogas ilícitas y víctimas. En octubre 18 de 2012 se instalan los diálogos de paz en Oslo, Noruega. Iván Márquez como jefe de la delegación de las FARC se dirige al mundo con un discurso en el que se les confirma la filiación ideológica y en el que se confirma también el interés de las mismas por restaurar la justicia social en Colombia. En noviembre del mismo año se conoce que Humberto de la Calle sería el vocero del GN.

Lo que pretendía el GN era llegar de manera efectiva a acuerdos y no indefinir eternamente las negociaciones. Por eso en mayo de 2013 se llega al acuerdo del primer punto de la agenda y la llaman "Hacia un nuevo 
campo colombiano: reforma rural integral". En este acuerdo parcial se enfoca en el papel del pequeño productor y las facilidades que se le otorgarán a este para el acceso y distribución de tierras. Estos acuerdos buscan promover la producción agropecuaria y otorgar el acceso a las tierras al mayor número de campesinos mediante el Fondo de Tierras para la Paz. Como propósitos para el nuevo acuerdo referente al primer punto sobre lo agrario, se establece que habrá planes de vivienda, agua potable, la capacitación y demostración de técnicas para sacar mayor provecho de las riquezas naturales. Ese mismo 2013, pero en noviembre, se cierra un nuevo ciclo de diálogo habiendo concretado el segundo punto de la agenda sobre la participación política.

Tal y como lo sugería Chernick, en el gobierno Santos y bajo el marco de los diálogos de paz que se sostenían en La Habana, las FarC solicitan que una comisión se encargue de esclarecer desde la perspectiva histórica las causas del conflicto y su prolongación a partir del documento que ya se había elaborado desde el Grupo de Memoria Histórica en su documento "Basta ya". De ahí surge el informe de la Comisión Histórica del Conflicto y sus Víctimas que tiene como fin la compresión desde sus raíces más profundas del origen del conflicto colombiano y sus directos responsables, esto con el fin de que sirva de insumo para una futura Comisión de la Verdad. En mayo de 2014 se terminan por acordar finalmente los puntos del tema sobre el problema de las drogas ilícitas. Justo ese día tanto el ELN y las FARC concuerdan en bajar el fuego a razón de las elecciones presidenciales, cuya segunda ronda fue disputada por el ganador de la primera, Óscar Iván Zuluaga y el presidente para ese momento, Juan Manuel Santos.

En 2014 se dan a conocer de manera parcial los acuerdos llevados a cabo hasta ese momento en lo respectivo a los primeros tres puntos: lo rural, la participación política y las drogas ilícitas. A pesar de los diálogos que se mantenía en Cuba, en noviembre de ese año, en Chocó fueron tomados en contra de su voluntad por las farC al General Rubén Darío Alzate, el cabo primero Jorge Rodríguez y la abogada Gloria Urrego. Por tal hecho, el 17 de noviembre el presidente Juan Manuel Santos suspende los diálogos sostenidos en La Habana y condiciona la reanudación de los mismos al hecho de retornar con vida a las tres personas retenidas. El 30 
del mismo mes se liberan los tres secuestrados. En este sentido Chernick también habría coincidido, pues según el experto de procesos de paz, las negociaciones se deben llevar a cabo en el medio del cese bilateral, de ser posible. Sin embargo las condiciones materiales eran otras y las negociaciones debían continuar pese a todo tropiezo. Las Farc liberaron a los secuestrados y los diálogos continuaron, pero se determinó que habría un cese bilateral por un tiempo indefinido.

Hubo una fecha determinante para el proceso de paz y subsiguientemente para esta investigación. En mayo de 2015 el Consejo de Estado de Colombia determina que las FARC no son un grupo terrorista, no queriendo decir que no hayan cometido actos terroristas. Este cambio de estatus cambia el panorama porque se da el reconocimiento del enemigo no como un agente a eliminar, sino como un agente con el que se debe dialogar a través de la argumentación para llegar a acuerdos comunes básicos. Ahora bien, lo discutido en La Habana era que la palabra final sobre la aceptación de los acuerdos de paz la tenía el pueblo colombiano. Para las FARC y el GN era claro que la refrendación de lo acordado debía darse por democracia directa a través de un plebiscito, por eso se aprueba en el Senado un proyecto para la refrendación. Para diciembre se logra finalizar el ciclo de diálogos en torno al punto final, el de las víctimas.

El 24 de agosto de 2016 se fijó en La Habana el acuerdo final para la dejación de armas y el cese al fuego unilateral, y ya un mes antes la Corte Constitucional colombiana había aprobado el plebiscito por la paz. Luego en septiembre de 2016 y en presencia de distintos mandatarios de todo el mundo se firma en Cartagena de Indias el acuerdo final de paz, un hecho definitivamente histórico para la nación colombiana y en general para Latinoamérica y el mundo.

La jornada nacional en la que la población civil votaba a favor o en contra de los acuerdos de paz se llevó a cabo el 2 de octubre de 2016. La sorpresa fue que los votantes del "no" fueron mayoría, y los grandes partidarios del "sín" debieron aceptar su derrota. Pero, ¿acaso fracasaba así el esfuerzo más reciente por buscar la paz en Colombia a través del diálogo democrático? Muy de acuerdo con los principios discursivos, el GN continuó buscando la fórmula más democrática para alcanzar un acuerdo final. Así, tras la derrota en el plebiscito, el GN y las FARC aceptan escuchar 
las quejas de los opositores al acuerdo final. El 25 del mismo mes el presidente se encuentra con los opositores para reajustar los acuerdos. Debemos mostrar acá que el diálogo se mantuvo, a pesar de la negativa por vía directa del pueblo colombiano, las FARC y el GN continuaron buscando alternativas para ofrecer un nuevo acuerdo.

Al finalizar el 2016 la Corte Constitucional prueba el "fast track", un procedimiento legislativo especial que "con el propósito de agilizar y garantizar la implementación del Acuerdo Final para la Terminación del Conflicto y la Construcción de una Paz Estable y Duradera (Acuerdo Final) y ofrecer garantías de cumplimiento y fin del conflicto, de manera excepcional y transitoria se pondrá en marcha el Procedimiento Legislativo Especial para la Paz, por un período de seis meses, contados a partir de la entrada en vigencia del presente acto legislativo" (Corte Constitucional de Colombia, 2016). Las cosas así, en marzo de 2017 las FarC inician el proceso de entrega de las armas que tienen en su poder. Este proceso es supervisado por la ONU. Las primeras son entregadas el 17 de ese mes.

Lo que se venía después de eso era la ley que iba a encargarse de poner las pautas para juzgar a los excombatientes. Por eso en marzo el Congreso colombiano aprueba la creación de la Justicia Especial para la Paz, sistema que juzgará a los militantes de las FarC por los delitos cometidos. Dicha ley es la Justicia Especial para la Paz, que entró en vigencia el 28 de marzo de 2017.

Sin ir más allá, con los renovados intentos de alcanzar la paz en Colombia, se estarían posibilitando las condiciones que nuestros analistas proponen y que algunos mandatarios han intentado implementar, a saber, la participación de organismos internacionales que vigilen el compromiso de las participantes para cumplir con lo pactado, la vinculación de víctimas, el grupo guerrillero, el gobierno, la oposición, etc. Esto también nos permite renovar la confianza que tenemos los colombianos en que los conflictos del país pueden canalizarse por vías dialógicas, o lo mismo, por vías democráticas, posibilitando moralmente la apertura de los conflictos y el debate entre las partes.

Aunque no podemos dejar de reconocer en este punto que todo intento de diálogo racional, tal como nos lo advierte Adela Cortina (1988), siempre será visto como un intento estratégico de debilitar al enemigo 
para engañarlo y posteriormente reducirlo mediante el uso de la fuerza, con lo anterior nos queda sin embargo la confianza de que sí se pueden humanizar democráticamente los conflictos en un país que cumple más de medio siglo de violencia.

Como vimos en esta investigación, los esfuerzos por mantener un diálogo lejos de las vías violentas es lo que persiste en Colombia, y lo que se mostraba desde el marco teórico podría decirse que se materializó en este esfuerzo por construir la paz, que si bien no es perfecto, pues como se ha visto existen aún dudas e improvisaciones al respecto, era un paso necesario en un país que busca garantizar la democracia y la igualdad. Esto sigue en construcción, pues la paz no es cuestión de una mera firma, la paz es construcción, pero lo que se debe anotar en estos resultados es que la actitud dialogante entre dos extremos fue el paso primordial para lograr unos acuerdos que le dan vida a la esperanza de un país sin guerra. Esta actitud dialógica debe reproducirse, debe enseñarse y ponerse en práctica, pues solo a través del reconocimiento de la diferencia es que se construye una democracia.

\section{CONCLUSIONES}

En la Colombia de los diálogos de paz en la Habana, hemos comprobado que se renuevan los antecedentes de dialogar racionalmente para resolver los conflictos bélicos entre el grupo guerrillero y el Gobierno, tratando de canalizar una vez más, por vías democráticas, la posibilidad de que las diferencias entre los bandos opuestos se discutan políticamente. Por nuestra parte creemos que con esto se confirma la posición de Apel sobre la disposición humana de buscar en el diálogo el único mecanismo legítimo que posibilita el conflicto sin recurrir a la violencia, porque a pesar de los periodos presidenciales que impusieron por vía de la guerra la pacificación del país, fueron miles las víctimas que resultaron de estos procedimientos beligerantes. Es indiscutible que nadie en ningún momento desea y ha deseado aportar una víctima más al conflicto armado, razón por la cual resulta emergente la canalización de las disputas y oposiciones con bases ideológicas diferentes, por vías políticamente correctas apelando a las instituciones democráticas. Con esto no queremos realizar una 
apología al gobierno de turno, sino más bien al recurso del diálogo en el escenario político como único mecanismo legítimo para generar y tratar los conflictos. Creemos además necesario la participación política de todas la sociedad civil y organizaciones independientes, porque la paz no se logra, como ya dijimos y como ya hemos vivenciado -un ejemplo de ello es el Frente Nacional- mediante el acuerdo pacifista de dos instancias en conflicto, sino mediante diálogos democráticos incluyentes que acojan la multiplicidad de voces que surgen en la esfera política. Por ello afirmamos la necesidad de la praxis de liberación como medio legítimo para exigir el reconocimiento y la participación de todos los afectados que se encuentran en condiciones adversas.

Ahora bien, como el diálogo racional parece ser una característica propia del ser humano y como la praxis de liberación es una acción que cualquier sujeto humano puede realizar en su cotidianidad basándose en los principios de liberación. Decía el filósofo colombiano Guillermo Hoyos que "es en los contextos mundovitales de la sociedad civil en los que se confrontan consensos y disensos, es donde se aprende a respetar a quien disiente, a reconocer sus puntos de vista, a comprender sus posiciones, sin tener necesariamente que compartirlos" (Hoyos, 1995, p. 74).

La deliberación, el respeto, la solidaridad como puente al reconocimiento, la co-responsabilidad, el ser consecuentes con nuestros pensamientos y decisiones es parte de la tarea que nos compete a los colombianos en un contexto donde la paz debe ser un asunto no sólo de políticos y agentes beligerantes que logran acuerdos, sino en el día a día de cada uno de nosotros. Por eso damos a la educación un papel importante para alcanzar la paz deseada, en la medida que entendemos que ella no puede significar una meta a la que se llega firmando unos documentos, sino un punto de partida que nos compromete indefinidamente a aprender y mejorar cada día nuestras relaciones con los demás.

Es claro que no todos los asuntos que nos competen son susceptibles de acuerdos racionales y no pueden por lo tanto resolverse mediante el diálogo, pero sí podemos al menos acordar que aunque estamos en desacuerdo en ciertas cosas, no por ello debemos suprimir y eliminar al otro. Por tanto, estamos convencidos de la necesidad de aprender y enseñar a debatir, a argumentar, a tomarnos en serio la opinión del otro como válida en 
un reconocimiento recíproco de la diversidad de opiniones. Frente a esto creemos además que deben manejarse diversas posturas de la paz. La paz no puede tener un sentido unívoco y unilateral, sino que su significado se construye en la medida que entren en conflicto diversas opiniones sobre ella.

\section{REFERENCIAS}

Apel, K.-O. (1985). El a priori de la comunidad de comunicación y los fundamentos de la ética. En K.-O.Apel, La transformación de la filosofía (pp. 341-413). Madrid:Taurus.

Apel, K.-O. (2004). La ética del discurso como ética de la responsabilidad: una transformación postmetafisica de la ética de Kant. En K.-O. Apel, y E. Dussel, Etica del discurso y ética de la liberación. Madrid:Trotta, S.A.

Apel, K.-O. (2006). Ética del discurso, democracia y derecho de gentes. Dialnet, 1933. Recuperado de https://dialnet.unirioja.es/buscar/documentos?querysDismax.DOCUMENTAL_TODO=\%C3\%A9tica+del+discurso $\% 2 \mathrm{C}+$ democracia

Acuña,R.(s.f.).El proceso de paz fracasado de Belisario Betancur:Recuperado de:http://contrapunto.co/index.php?module $=$ notayi $=38-$ el-proceso-de-paz-fracasado-de-belisario

Ballén Molina, R. (2009). ¿Cómo terminar nuestra guerra? En Diálogos de saberes, pp. 37-48. Ciudad: editorial.

Chernick, M. (1996). Aprender del pasado: Breve historia de los procesos de Paz en Colombia (1982-1996). Colombia Internacional, 36, Doi: 10.7440/ colombiaint36.1996.02

Corte Constitucional de Colombia. (13 de Diciembre de 2017). Recuperado de http://www.corteconstitucional.gov.co/comunicados/No.\%2052\%20comunicado\%2013\%20de\%20diciembre\%20de\%202016.pdf

Cortina, A. (1988). Fundamentación pragmático-trascendental de una ética argumentativa. En A. Cortina, Razón comunicativa y responsabilidad solidaria (pp. 79155). Salamanca: Sígueme.

Cortina, A. (1988). Una política responsable y solidaria. En A. Cortina, Razón comunicativa y responsabilidad solidaria (págs. 181-219). Salamanca: Sígueme.

Cortina, A. (2008). Ética. Madrid: Akal.

Dussel, E. (2009). La ética del discurso de Karl-Otto Apels. En La Ética de la Liberación en la edad de la Globalización y de la Exclusión (pp. 180-188). Madrid:Trotta. 
Federación Colombiana de Municipios. (9 de mayo de 2014). Recuperado de https://www.fcm.org.co/Documents/Historia\%20de\%20los\%20Procesos\%20 de\%20Paz\%20en\%20Colombia\%20MF.pdf

González González, F. E. (2014). Poder y violencia en Colombia. Bogotá D.C.: Odecofi-Cinep.

Grupo de Memoria Histórica. (2013). ¡Basta ya! Colombia: memorias de guerra y dignidad. Bogotá: Imprenta Nacional.

Humanas Colombia. Centro regional de derechos humanos y justicia de género. (s.f.). Obtenido de Cronología de los diálogos con las FARC-EP. Recuperado de: http://www.humanas.org.co/pagina.php?p_a $=82$

Kant, I. (1795-2003). La paz perpetua. Madrid: Editorial del cardo.

Kant, I. (2000). Crítica de la razón práctica (séptima edición, traducción de Rodríguez Aramayo). Madrid: Alianza.

Pizarro, E. (2017). Cambiar el futuro. Bogotá D.C.: Debate.

Reyes, R., Gómez, J., Losada, A., París, A., y Trinidad, S. (21 de febrero de 2002). Colombia - Mesa nacional de diálogo y negociación: Comunicado de las FARC. Recuperado de: http://reliefweb.int/report/colombia/colombia-mesa-nacional-de-di\%C3\%A1logo-y-negociaci\%C3\%B3n-comunicado-de-las-farc

Santos, B. D. (2017). Democracia y transformación social. Bogotá D.C.: Siglo del Hombre Editores.

Segura, H. G. (13 de marzo de 2015). De comisiones de paz en la historia de Colombia. Recuperado de: http://www.elespectador.com/noticias/politica/ de-comisiones-de-paz-historia-de-colombia-articulo-549064

Tovar, L. (1996). Ética discursiva y conflicto. Aproximaciones a Apel desde Colombia. Concordia, (pp. 205-316).

Valencia, L. (02 de 05 de 2015). El fracaso de la comisión histórica del conflicto. Recuperado de http://www.semana.com: http://www.semana.com/opinion/articulo/ leon-valencia-el-fracaso-de-la-comision-historica-del-conflicto/426078-3 
